\title{
LA REFORMA CONSTITUCIONAL DE 2019 SOBRE SEGURIDAD Y JUSTICIA*
}

\author{
THE CONSTITUTIONL REFORM OF 2019 ON SECURITY \\ AND JUSTICE
}

\section{Sergio GARCÍA RAMÍREZ**}

RESUMEN: Esta reseña legislativa ofrece una visión panorámica acerca de varias reformas a la Constitución Política de los Estados Unidos Mexicanos iniciadas en 2018 - con diversos antecedentes - y culminadas en 2019. Esas reformas, que se produjeron en el marco del denominado "Plan Nacional de Seguridad y Paz" (2018-2024), del 14 de noviembre de 2018, presentado por el presidente de la República, atañen al régimen de seguridad pública y justicia penal. Estas reformas, contempladas desde la perspectiva de los derechos humanos, implican un giro muy importante en el régimen de seguridad y justicia previsto en la Constitución. Sin embargo, siguen el rumbo y atienden a los criterios que informaron esta materia a lo largo de los últimos lustros.

Palabras clave: seguridad pública, justicia penal, guardia nacional, policía, fuerzas armadas, procedimiento penal, medidas cautelares, prisión preventiva, extinción de dominio.
ABSTRACT: This study offers a panoramic view of several reforms of the Mexican Constitution that took place during 2018 and 2019. Those that occurred in the context of the so-called "National Security and Peace Plan" (2018-2024), dated November 14, 2018, presented by the president of Mexico, verse on public security regime and criminal justice. These reforms, seen from a human rights perspective, imply a very important turn in the security and justice regime enshrined in the Constitution. However, they follow the course and meet the criteria that has nurtured this matter over the last five years.

Keyzords: Public safety; criminal justice; national guard; police; armed forces; penal procedure; precautionary measures; preventive prison.

* Artículo recibido el 14 de noviembre de 2019 y aceptado para su publicación el 14 de diciembre de 2019.

** ORCID: 0000-0002-9164-8464. Investigador en el Instituto de Investigaciones Jurídicas. Profesor Emérito de la UNAM. Investigador Emérito del Sistema Nacional de Investigadores. Exjuez y expresidente de la Corte Interamericana de Derechos Humanos. Correo electrónico: sgriijunam@gmail.com.

Boletín Mexicano de Derecho Comparado, nueva serie, año LI, núm. 156, septiembre-diciembre de 2019, pp. 1709-1728.

Esta obra está bajo una Licencia Creative Commons Atribución-NoComercial-SinDerivar 4.0 Internacional, IIJ-UNAM. 
En las últimas semanas de 2018 y los primeros meses de 2019 se promovieron y produjeron diversos cambios de gran relevancia en preceptos constitucionales relacionados con dos temas de suma trascendencia para la vida social y la actuación de los órganos del poder público: la seguridad y la justicia, dentro de la vertiente penal. No sobra recordar la importancia que revisten ambas cuestiones para el orden jurídico y social, especialmente desde la perspectiva de los derechos humanos y la construcción y preservación del sistema democrático en su vertiente integral, a la que alude el artículo 3o. de la Constitución general de la República.

Invoco esa importancia de aquellos temas como justificación de esta breve reseña, con la que procuro acompañar - como lo he hecho en otras publicaciones, a lo largo de 2019- al abundante análisis de los nuevos preceptos constitucionales. El examen de las disposiciones que emergieron en 2018 y 2019 se ha emprendido a través de libros y artículos, seminarios y coloquios diversos celebrados en distintos escenarios, entre ellos el Instituto de Investigaciones Jurídicas de la Universidad Nacional Autónoma de México, la Academia Mexicana de Ciencias Penales y el Instituto Nacional de Ciencias Penales (Inacipe).

Es bien conocida la relación - siempre inquietante y a menudo controvertida - que existe entre el reconocimiento y la tutela de los derechos básicos del individuo, a los que calificamos como "derechos humanos", y el ejercicio del poder político constituido en Estado, depositario del "monopolio de la violencia" - o más precisamente, el "monopolio de la fuerza", que puede ser violencia-, que despliega un amplio arsenal de instrumentos, a menudo demoledores, para cumplir su misión original como garante de la seguridad y administrador de la justicia. Hay una copiosa doctrina, que ocupa a estudiosos de los siglos XVIII a XXI, en torno a esta materia. Por supuesto, no pretenderé acoger en una reseña legislativa esa doctrina, que se expande a medida que cambian las condiciones de la vida social, se altera el panorama de la criminalidad y aparecen nuevas exigencias sociales y políticas a propósito de la seguridad y la justicia.

En la trascendente reforma penal que alumbró al cabo del siglo XVIII, movida por ideas humanistas y liberales, se advirtió que la legislación penal - y las prácticas que ésta propicia - constituye un buen indicador sobre el imperio de la libertad o de la tiranía que prevalecen en una sociedad y la orientan y caracterizan. Esta idea mantiene su vigencia y su 
eficacia. A menudo se previene sobre la función reveladora que poseen las cárceles, las corporaciones policiales, los tribunales, las fiscalías, acerca de las convicciones públicas y el desempeño del poder.

Tómese en cuenta que, como se ha subrayado con frecuencia, en el ámbito de la seguridad - o de lo que se invoca como tal - y la reacción penal frente a la conducta ilícita, comparecen el poder público y el individuo - a título de imputado o de víctima del delito - que protagonizan un desencuentro entre fuerzas desiguales, encuentro que puede desbocar las tensiones autoritarias y menguar las defensas y garantías del individuo. Este es el escenario en el que han operado u operarán las disposiciones que comentaré en esta reseña.

Al cabo de la campaña electoral de 2019, que culminó en la elección federal del 1o. de julio del mismo año, se presentaron al país un conjunto de propuestas relacionadas con los graves problemas de seguridad pública que han caracterizado la etapa presente en la vida de México, y que anteriormente motivaron sendas reformas de diverso rango, sobre todo a partir de 1993. Esos problemas abarcan el incremento - a veces desmesurado - de la criminalidad, tradicional o "evolucionada", y las modificaciones que ello introduce en la acción del Estado. De las propuestas adelantadas durante la campaña electoral derivaron cambios constitucionales de gran alcance, a los que me referiré en esta nota, así como innovaciones legales e institucionales.

La primera presentación "oficial" de las sugerencias de reforma corrió a cargo del denominado "Plan Nacional de Seguridad y Paz 2018-2024", presentado por el presidente electo de la República el 14 de noviembre de 2018, documento con gran fuerza política, aunque no fuera jurídicamente vinculante de manera directa e inmediata. Poco después llegó, al amparo de ese Plan y de las propuestas que formuló, una iniciativa de reformas constitucionales ante la Cámara de Diputados del Congreso de la Unión - primer acto en el proceso total ante el Constituyente Permanente-, suscrita el 21 de noviembre de 2018 por varios legisladores del grupo parlamentario del Movimiento de Renovación Nacional (Morena), fracción mayoritaria en ambos cuerpos legislativos del Congreso de la Unión.

En la exposición de motivos de esta iniciativa se hizo notar, como concepto central y determinante, que "la obligación primera de cualquier Estado es preservar la integridad de la población ante toda suerte de amenazas". Asimismo, los autores del citado Plan y de la propia iniciativa se 
refirieron, en términos enfáticos, al notorio incremento de la criminalidad en la República y al fracaso de las medidas adoptadas para enfrentarla, lo cual trae como consecuencia la imperiosa necesidad de proveer un nuevo modelo de seguridad - con sus conexiones con la justicia penal- que frene y revierta la criminalidad. La aplicación de ese modelo tomaría en cuenta una serie de medidas preventivas vinculadas con diversos temas y problemas sociales, no sólo la actuación persecutoria de los delitos.

La reforma constitucional propuesta implicó cambios de gran calado en preceptos de la parte dogmática y de la parte orgánica de la ley suprema, a saber: los artículos 10, 16, párrafo quinto; 21, párrafo noveno y párrafo décimo y su inciso b); 31, fracción III; 35, fracción IV; 36, fracción II; 73, fracción XXIII; 76, fracciones IV y XI, y 89, fracción VII; adiciones como párrafos décimo primero, décimo segundo y décimo tercero al artículo 21; y derogación de las fracciones XV del artículo 73 y I del artículo 78, todos bajo el común denominador de la Guardia Nacional.

El proceso corrió con intensidad y visibilidad en las tres etapas que derivan del régimen de reforma constitucional: la primera, ante la Cámara de Diputados, instancia de origen; la segunda, ante el Senado, y la tercera, ante las legislaturas de las entidades federativas, con arreglo al proceso dispuesto por la ley suprema. También implicó consultas a diversos opinantes en distintos sectores: gobierno y sociedad civil, como adelante mencionaré. En los términos de las disposiciones constitucionales vigentes, una vez alcanzada la aprobación del Congreso federal, hubiera bastado con la de diecisiete congresos locales, pero se optó por aguardar a que todas las entidades de la Unión aprobaran los cambios. Esto daría mayor legitimidad - se dijo - a la reforma que finalmente rigiera.

Ante las dos cámaras del Congreso de la Unión se desarrollaron intensos debates y se emitieron varios dictámenes, que recogieron el resultado de aquéllos, y en ocasiones aportaron algunas variantes a los planteamientos originales. En la deliberación realizada ante los cuerpos legislativos - y, desde luego, en el debate público, que fue importante y vehementeintervinieron tanto los propios integrantes del Congreso como los gobernadores de los estados, presidentes municipales, académicos, miembros de organismos públicos diversos y representantes de corporaciones de la sociedad civil. Todos comparecieron ante los legisladores y dieron cuenta de un amplio conjunto de observaciones. 
Los dictámenes elaborados para informar el criterio de los cuerpos legislativos fueron los siguientes, que menciono en orden cronológico: 1) de la Comisión de Puntos Constitucionales de la Cámara de Diputados, el 21 de diciembre de 2018 (al que se agregaron opiniones de las comisiones de Seguridad Pública y de Gobernación); 2) de la misma comisión, el 16 de enero siguiente, que revisó el anterior; 3) de las comisiones Unidas de Puntos Constitucionales y de Estudios Legislativos Segunda de la Cámara de Senadores, el 19 de febrero de 2019, a partir de la minuta remitida por la cámara de origen; 4) revisión de aquél acordada por la Junta de Coordinación Política y representantes de los grupos parlamentarios, el 20 de febrero, y 5) documento final en la Cámara de Diputados (considerando la remisión del proyecto por parte del Senado), del 28 del mismo mes. Hubo prácticamente unanimidad favorable - con salvedad de un voto - tanto en la Cámara de Senadores como en la de Diputados. En la noticia sobre el éxito de la votación se proclamó el carácter democrático del proceso, que permitió alcanzar ese resultado.

Es necesario considerar en esta reseña, igualmente, las reformas incorporadas en el mismo periodo de trabajos legislativos en otros preceptos constitucionales, en virtud de la conexión que guardan con los que he mencionado, y atendiendo al hecho de que todos ellos han traído consigo un nuevo régimen penal, determinado por motivos comunes y atento a los mismos problemas de inseguridad pública. En consecuencia, me referiré también a dos figuras del nuevo derecho mexicano, que surgieron en 2008 y anidaron en la reforma de 2018-2019.

Esas figuras, muy preocupantes en concepto de numerosos analistas y de buena parte de la opinión pública, son: a) la prisión preventiva oficiosa — regulada por la reforma de 2008 y modificada por la de 2019-, a la que se refirieron el dictamen elaborado en la Cámara de Senadores (cuerpo de origen de esta reforma), el 6 de diciembre de 2018, y los dictámenes formulados en la de Diputados (revisora) el 16 de enero de 2019 y el 19 de febrero siguiente, y b) la extinción (o privación) de dominio, regulada en los artículos 22 y 73, fracción XXX, de la Constitución, promovida en la Cámara de Diputados el 30 de marzo de 2017, con dictamen favorable del 28 de abril del mismo año, remitida al Senado y dictaminada el 15 de noviembre de 2018, con retorno a la Cámara de Diputados y dictamen en ésta el 18 de diciembre. 
El punto central que abordan el Plan de Seguridad y Paz, de 2018, la iniciativa de los legisladores de Morena y la más amplia reforma constitucional de 2019, tiene que ver con la institución a cargo de la prevención e investigación de los delitos; esto es, la función de policía en sentido estricto. El Constituyente de 1916-1917 distinguió claramente entre la policía investigadora - entonces llamada "judicial" - y la administrativa, preventiva o gubernativa, sin funciones de investigación criminal. Este deslinde se moderó, e incluso se diluyó en el curso de varias décadas.

Acerca de la policía, personaje crucial del sistema penal, ha habido - y hay, por supuesto - fuertes señalamientos críticos y constantes requerimientos de profundo cambio en la organización y el desempeño policial. Generalmente ha sido desfavorable el concepto social en relación con la policía; el descrédito se incrementó en los últimos años. En un importante documento generado en 2011 por la Universidad Nacional Autónoma de México y el Instituto Iberoamericano de Derecho Constitucional, denominado Elementos para la construcción de una política de Estado para la seguridad y la justicia en democracia, consecuencia de una conferencia internacional celebrada en ese año, se instó a llevar a cabo una reforma de fondo que aportara un nuevo modelo policial.

En ese documento de 2011 se dijo que "la reforma policial parte de la responsabilidad política de construir políticas públicas democráticas de seguridad: la policía sigue a la política de seguridad, y ésta a la política social". Asimismo, se insistió en que "de la construcción de comunidades seguras y policías modernas y profesionales en los municipios se sigue el establecimiento de Estados seguros, y de un país seguro. Nunca es al revés. La reforma policial debe apuntar a la configuración de una policía más civil, democrática y eficiente, con un amplio reconocimiento ciudadano". En seguida, se afirmó que "la base original para construir esas políticas públicas es el municipio, que es el punto a partir del cual se deben enfocar los esfuerzos de reconstrucción policial para trascender posteriormente a las esferas estatal y federal".

La reforma de 2019 marchó por otro rumbo. El énfasis se depositó en: a) una nueva corporación (con ciertos antecedentes históricos, que no viene al caso analizar ahora), la Guardia Nacional, diseñada — se dijo - a ejemplo de instituciones similares que han arraigado en otros países y alcanzado en ellos buenos resultados; b) la reorientación de las fuerzas armadas hacia tareas de seguridad pública, reorientación anunciada expresamente en el 
Plan Nacional al que me he referido, y c) cierta consideración - que estimo menor y carente de eficacia - con respecto a las corporaciones policiacas locales (estatales y municipales), que en concepto de muchos observadores y al amparo de la experiencia y de los resultados acumulados hasta ahora debió ser la pieza primordial de la seguridad pública.

Adelantaré aquí que los dos extremos más relevantes del examen desarrollado dentro y fuera del Congreso con respecto a la reforma constitucional emprendida a partir del Plan Nacional y la iniciativa presentada por los diputados de la fracción parlamentaria de Morena fueron, por una parte, la distribución de facultades y tareas entre las autoridades federales y locales, mirada desde la óptica del sistema federal que hemos adoptado (siempre en movimiento), y por otra parte, el carácter civil o militar que se desea imprimir a la función del Estado sobre seguridad pública, y por lo tanto, la naturaleza y la orientación de los organismos que tienen a su cargo - y tendrán, en el futuro - el cumplimiento de esa función. Se discutió ampliamente la merma de facultades de las autoridades locales que provocaría la propuesta de reforma constitucional, y se manifestó reiteradamente el temor que suscita la intervención de las fuerzas armadas en cuestiones de seguridad pública: "militarización" de la seguridad, fue un concepto frecuentemente mencionado.

En los últimos años se ha dispuesto crecientemente de las fuerzas armadas para apoyar acciones en materia de seguridad pública. La circunstancia de grave inseguridad y la incompetencia de las corporaciones policiales ordinarias para afrontar la delincuencia, especialmente en su expresión de "crimen organizado", favoreció la intervención constante del ejército y la armada, que halló un marco político y social en la llamada "guerra contra el narcotráfico", estrategia dominante en el curso de varios lustros, hoy severamente criticada.

Esa política no tuvo asidero constitucional claro y suficiente, tomando en cuenta la disposición constitucional que limitaba el quehacer de esas fuerzas en tiempo de paz. En efecto, el artículo 129 de la ley suprema dispuso: "en tiempo de paz, ninguna autoridad militar puede ejercer más funciones que las que tengan exacta conexión con la disciplina militar". Y es claro que la seguridad pública - a diferencia de otras vertientes de la seguridad, como la nacional - no tiene esa exacta conexión, sin perjuicio de que las cosas ocurran de otra manera en circunstancias críticas y bajo la responsabilidad última de la autoridad civil. 
En virtud de que el empleo de las fuerzas armadas en el ámbito de la seguridad pública motivó constantes debates, surgió la necesidad de "legitimar" su presencia a través de una legislación adecuada a la circunstancia en la que aquéllas operaban. Fue así que se expidió la cuestionada Ley de Seguridad Interior, promovida por el Ejecutivo, aprobada por el Congreso de la Unión y publicada el 21 de diciembre de 2017. La aparición del mencionado ordenamiento se acompañó con frecuentes cuestionamientos. La ley tropezó en la Suprema Corte de Justicia, que la declaró inconstitucional en sentencia sobre la acción de inconstitucionalidad 6/2018 y sus acumuladas, notificada al Congreso de la Unión el 15 de febrero de 2018. Por lo tanto, quedó un "vacío" en este espacio de la actuación del Estado, vacío insatisfactorio y peligroso.

La legislatura y el gobierno electos en 2018 optaron por dar un giro a esta normativa, giro que se produjo al amparo de la discusión sobre la Guardia Nacional, a la que aludiré adelante. En el marco de ese importante viraje se resolvió y expuso el reencauzamiento de las fuerzas armadas; para ello era necesario reformar la Constitución. En la exposición de motivos de la iniciativa de reforma constitucional del 20 de noviembre de 2018, documento medular del cambio, se indicó: "el Estado no puede asegurar el cumplimiento de la legalidad ni construir la paz sin el concurso de los institutos armados. El retiro de los soldados y marinos de las tareas de seguridad pública colocaría a diversas regiones y a sus habitantes en una total indefensión ante la criminalidad organizada".

En consecuencia, se propuso remontar las restricciones estatuidas en el artículo 129 de la ley suprema y facultar a las fuerzas armadas para intervenir en materia de seguridad pública. A fin de conciliar la necesidad de esta medida con la oposición que suscitaba, el Congreso introdujo un criterio de temporalidad que acota - pero ciertamente no modifica esencialmente- la intervención militar en asuntos de seguridad. El artículo quinto transitorio del decreto de reforma constitucional, laboriosamente construido, dispone:

Durante los cinco años siguientes a la entrada en vigor del presente Decreto (de reforma), en tanto la Guardia Nacional desarrolla su estructura, capacidades e implantación territorial, el Presidente de la República podrá disponer de la Fuerza Armada permanente en tareas de seguridad pública de manera extraordinaria, regulada, fiscalizada, subordinada y complementaria. 
La misma disposición transitoria añadió un dato relevante para la reconducción militar hacia la seguridad pública. Ordenó que el Ejecutivo - esto es, el presidente de la República, precisamente - informará sobre "el uso de esta facultad" en la presentación del informe anual que debe rendir al Senado sobre las actividades de la Guardia Nacional, conforme a la nueva redacción de la fracción IV del artículo 76 constitucional.

En otra ocasión he observado que el artículo quinto transitorio al que me referí se propone acomodar la Constitución a las condiciones de la realidad. Pone de manifiesto que es imposible prescindir de la presencia de las fuerzas armadas en el sector de la seguridad pública; es decir, en el enfrentamiento de la delincuencia. Consecuentemente, la nueva norma transitoria dota a las fuerzas armadas, del marco jurídico constitucional que no se había logrado anteriormente. De esta suerte, coloca a aquéllas en funciones de policía y abre un periodo de prueba de los compromisos políticos y jurídicos inherentes a la reforma constitucional y a la nueva política de defensa social, e implícitamente reconoce que la plena integración y operación de la Guardia no se logrará en muy corto plazo.

En el proceso de la reforma se aludió constantemente al indispensable deslinde entre el quehacer policial y la actividad militar, que toma en cuenta las funciones de cada corporación y las características que revisten la vocación y la preparación de sus respectivos integrantes. Entró en el escenario el derecho internacional de los derechos humanos, especialmente a través de la jurisprudencia de la Corte Interamericana de Derechos Humanos, cada vez más invocada en México. Fue así como en dicho proceso de reforma se invocó la jurisprudencia de ese tribunal supranacional, que acepta cierta intervención militar cuando no existe otra vía para brindar seguridad a la sociedad y combatir la criminalidad, sujetando esa intervención a una serie de principios que fijan sus fronteras, y que los autores de nuestra reforma constitucional dicen haber observado. Los criterios del tribunal regional corresponden - con diversos antecedentes de la misma jurisdicción - a la sentencia dictada en el caso Alvarado Espinoza vs México, el 29 de diciembre de 2009.

En aquella sentencia se afirma que la intervención de las fuerzas armadas deber ser:

a) Extraordinaria, de manera que toda intervención se encuentre justificada y resulte excepcional, temporal y restringida a lo estrictamente necesario 
en las circunstancias del caso; - b) Subordinada y complementaria, a las labores de las corporaciones civiles, sin que sus labores puedan extenderse a las facultades propias de las instituciones de procuración de justicia o policía judicial o ministerial; - c) Regulada, mediante mecanismos legales y protocolos sobre el uso de la fuerza, bajo los principios de excepcionalidad, proporcionalidad y absoluta necesidad y de acuerdo con la respectiva capacitación en la materia, y - d) Fiscalizada, por órganos civiles competentes, independientes y técnicamente capaces.

Como señalé, la institución de la Guardia Nacional es una pieza básica en las reformas normativas e institucionales en la materia que estoy comentando. Dadas las características de esta reseña legislativa, dejaré de lado los antecedentes de esta figura en el orden constitucional mexicano, y tampoco me ocuparé de las características que revisten ciertas instituciones extranjeras, que pudieran resultar similares a la mexicana - cuyos autores proclamaron este parentesco, fuente de inspiración de la reforma-, pero obedecen a las circunstancias propias de los países y las épocas en las que surgieron, muy diferentes de las nuestras. Obviamente, es importante e incluso indispensable el estudio comparado de las instituciones y las disposiciones, pero en todo caso se requiere, para que ese estudio devenga orientador y eficaz, tomar en cuenta - también comparativamente - las circunstancias en las que surgen y se desarrollan las normas y los organismos que éstas instituyen.

Antes de la reforma de 2018-2019, la Guardia Nacional se asociaba tanto a la jurisdicción federal como a las atribuciones de las entidades federativas. La reforma de 2019 excluyó la vinculación con los estados y abrió la puerta a la idea de coordinación entre los organismos federales y los estatales. En el arranque del proceso, la iniciativa de reforma constitucional de los legisladores de Morena planteó una adición al artículo 21 constitucional, que diría: "La Guardia Nacional es una institución del Estado que participará en la salvaguarda de la libertad, la vida, la integridad, y el pleno ejercicio de los derechos de todas las personas, protegiendo su seguridad, sus bienes, así como preservar el orden, la paz pública, los bienes y recursos de la Nación". La iniciativa de los diputados, que en su conjunto tenía un fuerte tono militarista, invocó "razones de peso, tanto de índole histórica como internacional, para adscribir a la nueva corporación al ámbito castrense"; la Guardia "nace como una institución adscrita al mando castrense".

Esta obra está bajo una Licencia Creative Commons

Atribución-NoComercial-SinDerivar 4.0 Internacional, IIJ-UNAM.

Boletín Mexicano de Derecho Comparado, núm. 156, pp. 1709-1728. 
Merced a la fuerte presión de los opositores a una reforma constitucional de esa naturaleza, en la propia Cámara de Diputados se afirmó el carácter "civil, disciplinado y profesional" de la Guardia Nacional, a título de institución de seguridad pública, y se postuló inscribir la siguiente fórmula en el antepenúltimo párrafo del artículo 21: la Federación

...contará con una institución policial de carácter y dirección civil denominada Guardia Nacional, responsable de las tareas de seguridad pública para la salvaguarda de la vida, la libertad, la integridad y el patrimonio de las personas, la preservación de los bienes y recursos de la Nación, así como la colaboración con las entidades federativas en los objetos anteriores.

Desde luego, la regulación propuesta, atenta al debate que se desarrollaba en el Congreso y fuera de él, debió ocuparse en un tema de gran importancia, cuya solución acogiera los planteamientos en pugna. Por ello, el dictamen de los diputados del 16 de enero de 2019, que moderó los términos de la iniciativa, señaló que la Guardia Nacional quedaría "adscrita a la Secretaría del ramo de Seguridad", pero también declaró que la Guardia "tendrá una Junta de Jefes de Estado Mayor compuesta por integrantes de las dependencias de los ramos de Seguridad, Defensa Nacional y Marina".

En el mismo rumbo conciliador, el segundo dictamen de los diputados destacó la condición policial de la Guardia y su actuación en el marco de los principios constitucionales: "la formación, la capacitación y el desempeño de los integrantes de la Guardia Nacional se regirán por una doctrina policial fundada en la disciplina, el acatamiento de las órdenes superiores, el respeto a los derechos humanos y la perspectiva de género en el ejercicio de sus funciones".

En la norma finalmente aprobada, el antepenúltimo párrafo del artículo 21 indicó que "la Federación contará con una institución policial de carácter civil denominada Guardia Nacional, cuyos fines son los señalados en el párrafo noveno de este artículo"; es decir, aquellos asignados a la función de seguridad pública: "salvaguardar la vida, las libertades, la integridad y el patrimonio de las personas, así como contribuir a la generación y preservación del orden público y la paz social, de conformidad con lo previsto en esta Constitución y las leyes de la materia". 
Este régimen se atendría a los principios que han figurado en el mismo párrafo del artículo 21 a propósito de la función de seguridad a cargo del Estado: "legalidad, objetividad, eficiencia, profesionalismo, honradez y respeto a los derechos humanos previstos en esta Constitución”. Estos derechos son los mencionados literalmente en la propia ley suprema, al igual que los reconocidos en tratados internacionales, conforme a las estipulaciones de los artículos 1o. y 133 de la Constitución. En el enunciado de los fines a los que atenderá la Guardia Nacional se agrega "la coordinación y colaboración con las entidades federativas y municipios, así como la salvaguarda de los bienes y recursos de la Nación".

En artículos transitorios del decreto de reforma constitucional quedó estatuida la integración de la Guardia, a partir de tres corporaciones, de las que se toman los efectivos que constituirán aquélla: Policía Militar, Policía Naval y Policía Federal (artículo segundo). Obviamente, la Guardia Nacional es un cuerpo mayoritariamente militar, que predomina en el panorama total de la policía del país.

Hubo un alivio a la excesiva centralización a través del artículo 4o. transitorio previsto en el dictamen de los diputados del 16 de enero de 2019, que señaló: "El Sistema Nacional de Seguridad Pública implementará un esquema de fortalecimiento del estado de fuerza y las capacidades institucionales de los cuerpos policiales, bajo objetivos cuyos resultados sean verificables". No dejaré de reiterar mi punto de vista, que coincide con el parecer de muchos especialistas en esta materia, e incluso de opinantes de diversos sectores sociales, en el sentido de que es verdaderamente indispensable fortalecer a las corporaciones policiales locales, sean estatales, sean municipales. Son éstas las instancias familiares para los ciudadanos en sus propias comunidades, que atienden cotidianamente, y cuyas características y necesidades conocen o deben conocer puntualmente.

En otro texto se previno, recogiendo sugerencias previamente aportadas en el proceso de reforma y reelaboradas para dar paso al consenso parlamentario, que la Guardia contaría con una "instancia de coordinación operativa interinstitucional formada por representantes de las secretarías del ramo de Seguridad, de la Defensa Nacional y de Marina”.

El artículo sexto transitorio del decreto de reforma, que también se refiere detalladamente a la conformación y funcionamiento de la Guardia Nacional y a la homologación de disposiciones aplicables a ésta y a la fuerza armada permanente, encomienda esa tarea a las secretarías de Se-

Esta obra está bajo una Licencia Creative Commons

Atribución-NoComercial-SinDerivar 4.0 Internacional, IIJ-UNAM.

Boletín Mexicano de Derecho Comparado, núm. 156, pp. 1709-1728. 
guridad y de Defensa y Marina, que la cumplirán a lo largo de cinco años. Parece que una vez transcurrido ese plazo las fuerzas armadas retornarán a sus cuarteles, puesto que ya se contará con una Guardia Nacional suficiente y competente para contener el asedio del crimen.

No han faltado expresiones de escepticismo con respecto a ese retorno de las fuerzas armadas a sus cuarteles. Sucede que la asunción de nuevas atribuciones y la ocupación de nuevos espacios de poder constituyen factores poderosos para la redefinición de las instituciones y la previsión de su porvenir. Difícilmente se prescindirá de esas atribuciones y se abandonarán esos espacios. Sin embargo, conviene mantener en vigilia la expectativa de regreso a la normalidad, que implicaría la revisión y reversión de muchas decisiones adoptadas para hacer frente a circunstancias que consideramos excepcionales, sustento de medidas que también revisten ese carácter.

En este mismo orden de consideraciones, corresponde analizar la injerencia de la Guardia Nacional en la investigación de los delitos. Al respecto, tómese en cuenta que el artículo 21 de la Constitución ordena que "la investigación de los delitos corresponde al Ministerio Público y a las policías, las cuales actuarán bajo la conducción y mando de aquél en el ejercicio de esta función". Antes de que se contara con una reglamentación de los mandamientos constitucionales, era natural que los analistas de esta materia se preguntaran si subsistiría la facultad indagatoria de delitos que se pretendió atribuir a la Guardia Nacional, considerando que ésta es una institución policial, y que por eso podría caber en el término genérico "policías" que utiliza el primer párrafo del artículo 21 de la ley suprema.

Esa interrogante ha encontrado respuesta, no necesariamente alentadora, en el artículo 7o. de la nueva Ley de la Guardia Nacional, emitida para reglamentar la reforma constitucional sobre esta materia, y publicada el 27 de mayo de 2019. La fracción III de este precepto señala que la Guardia tendrá a su cargo "investigar la comisión de delitos, bajo la conducción y mando del Ministerio Público competente en el ejercicio de esta función". Como se advierte, queda de manifiesto que la Guardia tiene atribuciones investigadoras, a la manera de los cuerpos policiales previstos en el artículo 21 constitucional. Asimismo, del citado artículo 7o. se desprende que esas investigaciones podrán realizarse a instancia del Ministerio Público "competente". La expresión pudiera abarcar tanto al M. P. federal como al local, en sus respectivas competencias. 
La reforma constitucional atribuye al Senado la compleja función de "analizar el informe anual que el Presidente de la República" le presente acerca del desempeño y los resultados de la Guardia (artículo 76, fracción IV); pero la Constitución misma no prevé la consecuencia de ese informe. También compete al Senado "analizar y aprobar la Estrategia Nacional de Seguridad Pública, en el plazo que disponga la ley, previa comparecencia del titular de la secretaría del ramo. En el caso de que el Senado no se pronuncie en dicho plazo, ésta se entenderá aprobada" (idem, fracción XI). Esta facultad se relaciona con las prevenciones contenidas en los artículos 21, penúltimo párrafo, y transitorio cuarto, 2, 8.

La Ley de la Guardia Nacional se refiere al control parlamentario por parte del Senado a propósito del informe anual de actividades de la Guardia Nacional. Prevé un detallado conjunto de datos (artículo 97), a los que el Ejecutivo deberá agregar los que solicite, en su caso, la Cámara de Senadores (artículo 98), que "analizará y, en su caso, aprobará el informe dentro del mismo periodo ordinario de sesiones en el que haya sido presentado".

Hasta aquí el panorama de las normas constitucionales más relevantes acerca de la pieza fundamental acogida por el sistema penal para enfrentar la delincuencia: una pieza que militariza - directa o indirectamente - la función de seguridad pública a cargo del Estado mexicano y pone el mayor acento en la corporación federal integrada a toda velocidad, no tanto en la recomposición de las policías locales.

Como señalé en las líneas iniciales de esta nota, paso a reseñar otras dos aportaciones de las reformas constitucionales aprobadas en 2019 para prevenir y combatir la delincuencia, a saber: la prisión preventiva oficiosa y la extinción de dominio, que han suscitado, al igual que las anteriormente examinadas, un fuerte debate.

Para examinar la figura de prisión preventiva oficiosa, adoptada con gran acento en 2008 y extremada - bajo fuertes críticas - en 2019, es preciso recordar que la prisión preventiva misma es una medida cautelar que anticipa la restricción de algunos derechos - ante todo, el de libre desplazamiento personal - a la condena del imputado. Al igual que otras medidas cautelares, entra en tensión manifiesta con el principio - o presunción - de inocencia: ¿cómo afectar derechos de quien no ha sido procesado y condenado como responsable - probadamente- de un delito que efectivamente no ha cometido?

Esta obra está bajo una Licencia Creative Commons

Atribución-NoComercial-SinDerivar 4.0 Internacional, IIJ-UNAM.

Boletín Mexicano de Derecho Comparado, núm. 156, pp. 1709-1728. 
Sin dejar de advertir las contradicciones que surgen en la tensión entre el principio de inocencia y la restricción de derechos del imputado, los analistas de la prisión preventiva aceptan la procedencia de ésta en determinados supuestos: a) riesgo de que el imputado se sustraiga a la justicia; b) probabilidad de que aquél altere la marcha del proceso sustrayendo o destruyendo pruebas, y c) peligro que surge para otros participantes en el proceso, particularmente la víctima de la conducta ilícita. Este encauzamiento de la prisión preventiva implica un análisis casuístico de cada caso, que debe ser revisado y resuelto en sus propios términos, judicialmente, no a partir de "prejuicios legislativos" que se extiendan sobre "series" de casos en función del delito supuestamente cometido, y que excluyan el examen judicial y las consecuentes facultades (y responsabilidades) del juzgador.

Nuestra Constitución acoge tanto lo que podríamos llamar prisión preventiva ponderada, sujeta a la petición razonada del Ministerio Público y a la decisión reflexiva y motivada del tribunal, como lo que se ha denominado prisión oficiosa; esto es, necesaria, automática (puesto que no se pone en manos del tribunal la "posibilidad" de acordarla o prescindir de ella, sino se le ordena aplicarla), que no está sujeta al mismo razonamiento individualizado, sino sólo al delito que se atribuye al imputado. Es notorio que semejante imposición legislativa desconoce la naturaleza de la medida cautelar y le confiere un alcance que le es extraño.

En el proceso de la reforma de 2019 sobre seguridad y Guardia Nacional se llevó adelante la revisión del texto que la ley suprema adoptó en 2008 a propósito de la prisión preventiva oficiosa (artículo 19 constitucional). En esta materia, los antecedentes se localizan tanto en dicha reforma de 2008 como en varias iniciativas de reforma constitucional presentadas a la Cámara de Senadores y dictaminadas, en conjunto, el 28 de noviembre de 2018. La minuta aprobada por el Senado y enviada a la Cámara de Diputados se sustentó en un dictamen senatorial del 6 de diciembre de 2018. Una vez recibida la minuta en la Cámara de Diputados, se dictaminó el 19 de febrero de 2019. El pleno de esta cámara no acogió los términos del dictamen y optó por la regulación adoptada en la Cámara de Senadores.

A partir de 2008 y antes de la reforma de 2019, los supuestos genéricos de prisión preventiva oficiosa correspondían a delincuencia organizada, homicidio doloso, violación, secuestro, trata de personas (agregada en 
2011 ), delitos cometidos con medios violentos, como armas y explosivos, así como "delitos graves que determine la ley en contra de la seguridad de la nación, el libre desarrollo de la personalidad y de la salud". Desde luego, estas últimas categorías abren la puerta a infinidad de hipótesis, provistas por la razón o la imaginación del legislador. Es uniforme la convicción - por la naturaleza misma de las cosas - de que el homicidio es privación de la vida (con diversas modalidades), pero no lo es el contenido de la expresión "libre desarrollo de la personalidad", que puede implicar muy diversas figuras delictivas, además de las que últimamente ha recogido.

El dictamen elaborado en la Cámara de Diputados, que actuó como instancia revisora, pretendió reducir el amplio conjunto de supuestos de aplicación de la prisión preventiva aprobado por los senadores. Sin embargo, esta moderación no prevaleció, y el pleno de la Cámara volvió a la relación extensa, desatendiendo los criterios acuñados por la Corte Interamericana de Derechos Humanos en torno a los principios que es preciso observar para dar cierta racionalidad a la aplicación de esa medida cautelar. Esto implicará, naturalmente, el aumento de la población carcelaria de presos sin condena, que se había reducido en los últimos meses.

En la Cámara de Senadores se agregaron otros delitos, extremando así la aplicación de la prisión preventiva. En definitiva, el catálogo de hipótesis incluyó abuso o violencia sexual contra menores, feminicidio, robo de casa habitación, uso de programas sociales con fines electorales, corrupción tratándose de los delitos de enriquecimiento ilícito y ejercicio abusivo de funciones, robo al transporte de carga en cualquiera de sus modalidades, delitos en materia de hidrocarburos, petrolíferos o petroquímicos, delitos en materia de desaparición forzada de personas y desaparición cometida por particulares, delitos en materia de armas de fuego y explosivos de uso exclusivo del ejército, la armada y la fuerza aérea. Tras esas expresiones genéricas contenidas en la Constitución, conviene examinar cuál es el verdadero número de supuestos ilícitos abarcables, a discreción del legislador secundario, bajo algunos rubros propuestos por el Senado.

El artículo cuarto transitorio del decreto de reforma constitucional sobre esta cuestión ordena evaluar el régimen de prisión oficiosa "para determinar la continuidad de su aplicación, a partir de los cinco años cumplidos de la vigencia" de dicho decreto. La revisión abarcará tanto "la eficacia de esta medida cautelar" como "la eficiencia del sistema pe- 
nal acusatorio", tomando en cuenta para ello diversos elementos — "críticos" - provistos por fuentes oficiales y por organismos de protección de los derechos humanos. Es plausible, a mi juicio, que se lleve a cabo tanto la evaluación de la prisión preventiva oficiosa como del llamado sistema procesal acusatorio en su conjunto, para reflexionar sobre sus fortalezas - que las tiene- y sus debilidades - que han sido - frecuentemente señaladas.

Es pertinente aludir en esta reseña a otra medida penal de suma importancia adoptada por la reforma de 2019: la privación o extinción de dominio, engendrada por la de 2008, que durante los años de su aplicación no arrojó el éxito práctico que esperaban sus partidarios. Con frecuencia he indicado, y ahora reitero, que esta reforma de 2008 no sólo bifurcó el sistema penal mexicano, separando la regulación aplicable a la delincuencia ordinaria de la que se aplica a la organizada - y a otras expresiones de criminalidad-, y recogiendo así retazos del derecho penal del enemigo, sino también aportó novedades que "harían fortuna" - pero no para bien del Estado de derecho y la justicia, en mi concepto- en los años y las normas siguientes. Ahora tenemos una triple vía para enfrentar las consecuencias de los delitos: la ordinaria y tradicional, la especial acogida en 2008 (sobre la huella de la Ley Federal contra la Delincuencia Organizada, de 1996) y la "civil", concerniente a la extinción.

La medida de extinción de dominio, conocida en otras legislaciones que el Constituyente mexicano invocó como modelos (Estados Unidos, Honduras, Guatemala, Colombia, Italia, Brasil y Argentina), se propone afectar recursos de delincuentes - o de supuestos delincuentes, e incluso de incautos ciudadanos, inocentes de cualquier delito-, a través del apoderamiento de aquéllos por parte del Estado, que de esta suerte vulnera las fuentes de abastecimiento, los medios materiales y los rendimientos económicos de los delincuentes. Por supuesto, estos fines son plausibles, e incluso indispensables, pero la consideración de la materia no puede detenerse en la pertinencia de los fines, sino también examinar la legitimidad de los medios con los que se pretende alcanzar aquéllos.

Cuando la privación de dominio llegó al artículo 22 constitucional, en 2008, se dijo que el correspondiente procedimiento sería "autónomo del de materia penal”. Esta afirmación consuma una verdadera transmutación de los contenidos de las medidas que contempla. En efecto, la privación de marras se halla directa e inexorablemente vinculada con 
delitos, que son materia del derecho penal y debieran serlo del procedimiento respectivo.

Los supuestos de procedencia de la privación o extinción bajo la reforma de 2008 al artículo 22 constitucional fueron los siguientes, todos ellos constitutivos de delitos: delincuencia organizada, delitos contra la salud, secuestro, robo de vehículos y trata de personas, asociados a un conjunto de bienes señalados por el propio texto constitucional

En este campo, la reforma de 2019 se extendió sobre los artículos 22 y 73, fracción XXX, de la ley suprema. En el dictamen de los diputados del 11 de diciembre de 2018 se dijo que "la acción de extinción de dominio no reprime la realización de conductas penales (gloso: supongo que se quiso decir punibles o típicas penales), en consecuencia, no es en sí misma el castigo de quien ha violado la norma penal". Y el documento agregó, ahora con razón, que aquella extinción, "dentro de la estrategia de seguridad pública es considerada para atacar los fondos económicos con los cuales la criminalidad organizada corrompe y destruye la institucionalidad del Estado".

La argumentación insiste en la línea asumida desde la adopción de la figura en México

...la Extinción de Dominio (gloso: así en el original, con iniciales mayúsculas) es el procedimiento más eficaz para la recuperación de activos, ya que, como ha quedado mencionado, será de índole diferente al procedimiento jurisdiccional penal, siendo ahora un procedimiento, también jurisdiccional, pero de naturaleza civil, con un estándar probatorio diferente y acorde a la nueva naturaleza que se le pretende dar.

Esto hará que el método "no penal" adoptado resulte "eficaz y viable", además de que "no choca", en modo alguno, sigue diciendo el dictamen, con "el marco de respeto a los derechos humanos".

Cuando la privación de dominio apareció en el escenario del artículo 22 constitucional, hace relativamente poco tiempo, se dijo que ese procedimiento (jurisdiccional y, obviamente, "autónomo del de materia penal", aunque todos sus supuestos fueran evidentemente delictuosos) procedería en los casos de delincuencia organizada, delitos contra la salud, secuestro, robo de vehículos y trata de personas, con respecto a un conjunto de bienes señalados por el propio texto constitucional. 
La reforma de 2018-2019 al artículo 22, que establece un complejo conjunto de medidas de cooperación entre autoridades de diversos órdenes de gobierno, revisó y amplió el catálogo, al fijar una extensa relación de delitos para la aplicación de esta medida "no penal" que tiene su raíz en comportamientos "sí penales": hechos de corrupción, encubrimiento, delitos cometidos por servidores públicos, delincuencia organizada, robo de vehículos, recursos de procedencia ilícita, delitos contra la salud, secuestro, extorsión, trata de personas y delitos en materia de hidrocarburos, petrolíferos y petroquímicos.

La reforma al artículo 73 prevé la emisión de una ley de alcance nacional acerca de la privación de dominio. De esta suerte, avanza en el camino de la concentración de atribuciones penales en manos de la Federación - concentración que es centralización, aunque se hable de federalización-, y con ello modifica, como lo han hecho otras disposiciones de la misma o semejante naturaleza, el modelo del federalismo mexicano. Con esta referencia no pretendo cuestionar la concentración racional de la materia penal sustantiva en un solo ordenamiento - objetivo altamente deseable - como ya se ha hecho en el ámbito del procedimiento penal, las alternativas al proceso, la ejecución de condenas y la atención de niños y adolescentes en conflicto con la ley penal.

Desde luego, las cuestiones controvertibles que suscita esta afectación del dominio de una persona - cuestiones que erosionan derechos fundamentales, primordialmente el de propiedad y el debido proceso conducente a afectarla - no se hallan sólo en el precepto constitucional. Aparecen, muy abundantes, en la ley reglamentaria del 9 de agosto de 2019, que permite desposesiones fulminantes, antes de que se cuente con decisiones judiciales de fondo - desposesiones que corresponden a la lógica que informa la medida - La desposesión puede verse seguida por una asignación o disposición del bien, en licitación o en acuerdo directo, bajo la capa de programas de utilidad social.

Me he referido en la presente reseña a disposiciones constitucionales. Éste es el límite del somero examen que he desarrollado. Empero, hay muchas otras expresiones recientes de lo que creo pertinente denominar una regresión penal, muy inquietante y ominosa. Mencionemos, sólo por ejemplo, las reformas al Código Penal de Tabasco, del 31 de julio de 2019, que la vox populi bautizó como "ley garrote"; los cambios y agravamientos en el Código Penal de la Ciudad de México, del 1o. de agosto 
Esta revista forma parte del acervo de la Biblioteca Jurídica Virtual del Instituto de Investigaciones Jurídicas de la UNAM

de 2019 — normas vigentes todas ellas - y las reformas aprobadas por el Congreso de la Unión (aunque todavía no publicadas al tiempo de formular este comentario) acerca de diversos delitos fiscales, cuya comisión puede quedar encuadrada bajo el concepto de delincuencia organizada y acarrear, por ende, la aplicación de prisión preventiva. 